\title{
Study on Countermeasures of Unbalanced Quotation
}

\author{
YUN WAN ${ }^{1}$, LANG WU ${ }^{1}$ \\ ${ }^{1}$ Civil Engineering And Architecture, Jiangxi Science \& Technology Normal University, Nanchang, Jiangxi, China
}

\begin{abstract}
This paper takes the unbalanced quotation method in the process of project bidding as the research object, analyzes its common means, causes and possible consequences. Research shows that serious unbalanced quotation will disturb the normal process of bidding. Finally, from the perspective of the owner, put forward the response strategies before bidding, in bid evaluation and in project implementation.
\end{abstract}

\section{Introduction}

With the gradual opening of the construction market, the bidding work is gradually standardized from exploration to mature operation, and gradually forms a new situation of "enterprise independent quotation, market price formation".This not only represents a significant progress in China's engineering pricing technology, but also provides application space and opportunities for construction enterprises to adopt unbalanced quotations. In previous studies, people's attention has mostly focused on how construction companies can make full use of unbalanced quotation techniques to obtain as much profit as possible, and from the perspective of owners, how to deal with unbalanced quotations and prevent unbalanced quotations is particularly important to reduce the risk of the resulting.

\section{The connotation and means of unbalanced quotation}

Unbalanced quotation refers to the bidding price of an engineering project. After the total price is basically determined, how to adjust the quotation of each internal project so as not to increase the total price and not affect Winning the bid can also get more ideal economic benefits in settlement, and realize "collect money early and collect more money"[1]. The premise of this method is the engineering quantity list quotation, which emphasizes the separation of quantity and price, which is the separation of engineering quantity and unit price. When bidding, the contractor reports the unit price instead of the total price. Final settlement amount shall be based on actual completed project amount. The number of projects provided by the bill of quantities will vary according to the design and measurement depth of the consulting engineer, and there is definitely a gap with the actual construction. In fact, the total revenue received by the contractor is equal to the product of the amount of work that has passed the acceptance during the performance process and the corresponding unit price. Although the total project price is similar, due to the different unit price of each item in the bill of quantities at the time of quotation, the contractor's profit will also be different as a result, thus providing the contractor with an opportunity to obtain more profits.

As an experienced contractor, once the project is started, in addition to advance payment, every single project completed must strive for advance money. As the settlement of project funds is generally carried out according to the progress of the construction of the project, the trick is to increase the unit price of the work completed first in the list of quantities (such as start-up fees, temporary facilities, earth and stone works, foundation and structural parts) Etc.), the unit price of the work completed after the reduction (such as road surface, traffic signs, roof decoration, cleaning construction sites and scattered ancillary works, etc.) [2] .Although the unit price may lose money later, because the cost has been recovered in advance, the problem of capital turnover has been properly resolved, financial resilience has been improved, and appropriate interest income is provided, so long as the entire project can be guaranteed to be profitable. This revenue and expenditure curve is known overseas as a "front loading" allocation method, and its core is to strive for the negative occupation of funds under internal management. The overall result is that the unit price of the project with a small number of contracts is lower and the price is a little bit; the project with a larger number of units has a higher unit price and rich profits, but the entire project eventually makes money. This is one of the main principles of the unbalanced quote method. The unbalanced quotation methods often adopted by bidders mainly include the following situations:

- In order to speed up capital turnover, the prices of projects that can be settled at an early date, e.g., early measurement fees, foundation engineering, earthwork, etc., are higher; Quotations of later engineering projects, e.g., equipment installation and decoration engineering, etc., are reduced.

- After the calculation of the project volume, it is expected that the project price will increase in the 
future (when the calculation of the inventory project volume is incorrect), the unit price can be appropriately increased; the project price of the project that may be reduced can be reduced.

- The design drawings are unclear or wrong, and it is estimated that there will be revisions in the future; or if the project description is unclear, the price can be reduced and the price will be increased when future claims are made.

- The daily wage and the hourly unit price of the scattered construction machinery can be slightly higher than the corresponding unit price in the project unit price. Because these unit prices are not included in the bid price, it is more profitable to calculate according to the actual situation when they occur.

- The tentative project (arbitrary project or selected project) needs to be studied by the contractor to decide whether to implement it and which contractor will implement it after the start of construction. If the general contracting or estimation is likely to require construction, the unit price is reported to be high; the subcontracting or unable to determine a reduction in the price for non-necessary construction.

- In the integrated unit price contract, some project bidders require that the contract price be raised when the contract bid is used (this type of project is usually risky and can be settled by the quotation after completion. That is to say, all can be settled back); the remaining unit price items are reduced.

- In the bid negotiation, in order to reflect the sincere sincerity, keep the total price relatively stable, meet the bidder's price reduction requirements, reduce only the unit price of the project with a small amount of work, and give the contractor the illusion that the unit price on the bill of quantities has dropped significantly.

\section{Main causes and possible consequences of unbalanced quotation}

The bidding unit and the bidding unit are unified and opposed in the entire bidding process. Both parties are unified on the basic point that the quality and quantity are completed on time to complete the construction task, but the project cost is also opposed to each other. The bidders are pursuing the minimization of construction costs under the premise of ensuring the quality and duration of the project; the bidders are pursuing the maximization of corporate profits under the same premise. The contradiction of the bidding unit in the calculation of the project cost is the prerequisite for generating an unbalanced quote. At present, the competition in the construction market is intensifying. With the importance of pre-qualification of bidding units by the bidding unit, the level of commercial bids directly affects whether the bidding unit can win the bid. In order to reduce investment, some contracting units blindly reduce prices and pursue low prices; bidders often use lower prices in order to survive competition. This unhealthy method of market competition is the direct cause of unbalanced quotes.

Severe imbalanced quotations will disrupt the normal conduct of bidding. As the winning bidder was not profitable, it had to go all out to bargain with the construction unit and try to flood the project or change the project during construction. Especially in the middle and high-end decoration projects, labor costs and material costs are more expensive, and the prices of materials of different brands and specifications vary widely. Through the above methods, the construction unit adjusted the construction cost to its own advantage. Not only did the project settlement cost far exceed the winning bid price, but it also increased the profit margin of the construction unit. Therefore, as far as construction enterprises are concerned, unbalanced quotation is a bidding strategy and technique, while for employers, unbalanced quotation will lead to low bids, high price settlement, and bring great passiveness to project management. Usually during the construction cost audit process, it is often encountered that the cost is seriously distorted due to the unbalanced quotation in the bid. For example, an industrial workshop is roofed with steel structure. It is stipulated in the bidding document that the owner shall make a tentative construction cost for the roofing project, and all bidders shall include the tentative construction cost in the total quotation. After the bidder wins the bid, the owner shall designate the subcontracting project for the roofing project, and the subcontracting enterprise and construction cost shall be determined by separate bidding. In the bidding documents, it is not clear that the provisional cost of roofing works will not float down. In the process of bid evaluation, the judges did not pay enough attention to the floating details of commercial bids of bidders. They only scored the commercial bids against the total quotation and the total floating rate, and the one with higher business score win the bid. When the project to be audited was settled, it was found that the bid unit had an unbalanced price reduction in civil construction, installation and roofing under the condition that the total descent rate was unchanged. The rate is $4 \%$, and the sag rate of roofing works is $16 \%$. The construction contract signed with the successful bidder has clearly stated that the total cost of the project includes the cost of the roofing project (a quotation after floating down), and the settlement price of the roofing project is subject to the bidding price of the subcontracting enterprise. Just because the tentative cost of the roofing project is not specified in the bidding documents, and the negligence of the judges in the bid evaluation process has caused great economic losses to the owner.

\section{Coping strategies for unbalanced quotation}

Since the comprehensive unit price of each project in the bill of quantities includes management fee and profit (the size of the management fee depends on the operating status and management level of the bidder's company, while the total profit is related to the bidder's bidding 
strategy), this creates a more hidden space for construction enterprises to use the unbalanced bidding strategy. In the view of various unbalanced quotation means, the tendering unit should take corresponding countermeasures under the condition of not losing fairness and justice, and strive to standardize the project bidding activities, ensure the project quality, improve the investment efficiency, and safeguard the national and social public interests and the legitimate rights and interests of the parties to the bidding activities. The following three aspects should be done well.

\subsection{Focus on preparations before bidding}

Owners must work in accordance with the relevant national infrastructure procedures and strictly eliminate the "trilateral" project. They must be willing to spend energy and funds to do a good job of preparing for the project before bidding. The design of the plan, the correct calculation of the project cost price, and actively implement a reasonable low price to win the bid, while ensuring the legitimate rights and interests of the parties to the bid[3]. It can be roughly summarized as follows:

\subsubsection{Improve the design depth and quality of drawings.}

This is particularly important for projects bidding for a total price. According to the Tendering and Bidding Law, under the premise of good qualifications and credibility of the bidding enterprise, the project should be awarded at a reasonable minimum price that is not lower than the cost price, and one of the prerequisites for the correct calculation of the project cost price is complete and accurate construction. Illustration. At present, the design drawings of most projects fail to meet the construction requirements at the time of bidding, and a large number of supplementary designs and design changes will occur during the construction process, which results in the list of bids and the actual construction volume. Although the pricing method of the bill of quantities is generally based on a fixed comprehensive unit price and the model of the actual measurement of the bill of quantities, this also brings opportunities for bidders to implement unbalanced quotations. Therefore, the industry mainly reviews the design depth and quality of drawings to avoid the situation of "design while bidding", and uses construction drawing bids whenever possible to reduce the occurrence of engineering changes from the source;

\subsubsection{Control the price of materials.}

The bidding unit shall have sufficient time to conduct market surveys on the main materials involved in the project and keep up to date with the latest price information; clarify the brand, specifications and quality grades of various valuable materials with large price gaps; If it is difficult to determine the price of the materials described, it may be considered to use the unified price of the temporary pricing first (but the tentative price should be moderate, and the adjustment method for the items involving the tentative price should be specified in the bidding documents). Adjust it according to the actual situation in the future to block the loopholes;

\subsubsection{Improve the quality of the bill of quantities.}

The industry mainly attaches importance to the compilation quality of the bill of quantities, eliminates the kind of dependence on the bill of quantities as a reference, and ultimately needs to settle according to the actual settlement. The bill of quantities should be used as an important basis for bidding and completion settlement, and the core of project cost control the key to limiting unbalanced quotes. Unbalanced quotation is generally to catch errors such as missing items and calculation errors in the bill of quantities. Therefore, an experienced cost engineer must be responsible for this work[4]. The compilation of bill of quantities should be as thorough and detailed as possible and predictable. At the same time, the compilation of bills of quantities should strictly implement the "Code for Valuation of Construction Project Bills" and the "Code for Calculation of Bills of Construction Engineering". Items and omissions to prevent bidders from making use of possible changes in the list of items to make unbalanced quotes. The project characteristics of each item in the list must clearly, comprehensively and accurately describe the detailed work that needs to be completed by bidders, so that bidders can fully consider all the costs incurred in completing the list items, and avoid differences in understanding due to unclear descriptions. Causes unnecessary errors in bidding companies' quotation and affects the quality of bidding. The construction quantity of the construction project is disclosed in the form of a list. The starting point of competition for all bidders is the same, which prevents the black box operation and reflects the principle of open and fair competition. In the entire system operation process, the transparency, rationality and scientificity of bid evaluation have been improved, and bids lower than the cost price have been avoided, so that malicious bidding can be effectively prevented, and project quality and safe construction can be ensured.

\subsection{Attach importance to the evaluation of commercial bid}

First of all, the bidding unit should, on the premise of fully understanding its own project, entrust a responsible and experienced cost consulting company with the corresponding qualification level to compile the control price, so that it can really know what it is, so that it does not have to use the lowest price to win the bid to form vicious competition. The bidding unit may set a guide price for the unit price of each item on the list, and calculate the control price on this basis. Because the quotation of the bill of quantities is generally based on the integrated unit price method, the unit price of each project includes all costs except for fees and taxes, including direct engineering costs, management fees, and profits. Therefore, the guide price should also be the 
comprehensive unit price. That is to say, the control price. Use the same pricing method. The bidding unit may specify in the bidding documents that the control price is the highest price limit of the bidding unit, and each item of the list is quoted by the bidding unit independently, but it is stipulated that when the total quotation is lower than the control price, the quotation of each item shall not deviate from the guide price within a certain range, thereby limiting the unbalanced offer to a reasonable range. The key here is whether the determination of the guide price is reasonable, whether it can be basically the same as the market price, and eliminate excessive profits, at the same time, it includes reasonable costs and profits to prevent the construction unit from over-pressing the price. In the bid evaluation analysis, the bid evaluation team can use the guide price to analyze the reasons for the difference in quotes. In addition, as the main industry, it will give full play to the professional and technical advantages of intermediary agencies and conduct field inspections on the credit status of the proposed bidding unit. In particular, it should pay special attention to whether the project performance of the proposed bidding unit has caused economic disputes due to project settlement. Compilation and review of pre-qualification, bidding documents, and bid evaluation methods of bidding units.

Secondly, it is necessary to arrange as many engineering budget personnel as possible among the members of the bid evaluation expert group, appropriately increase the proportion of cost experts in the commercial bid evaluation group, and improve the system of clearing, evaluating, inquiring and determining bids; The vague matters in the bids require bidders to clarify or promise in writing, so as not to leave hidden dangers; at the same time, to ensure that the review time of commercial bids must not go through the field and be superficial. In the bid evaluation method, a reasonable deduction value is set for the imbalance of commercial quotations to limit unbalanced quotations. When evaluating bids, the comprehensive unit price, measure fee, and total price each account for a certain percentage. The comprehensive unit price and measure item of key projects are reviewed separately. Each evaluated reasonable minimum price will get the standard score. For the sub-item unit price reported by other bidders that is higher than a certain proportion, a certain point value of the standard point is deducted until the deduction is completed. In short, the unbalanced items in the bidding unit's commercial bids should be analyzed one by one, summarized and organized to form written materials, and unbalanced quotations involving large amounts can be abolished.

Finally, the bidding unit should timely organize the commercial bid inquiry of the bid winning unit, make full use of the enthusiasm of the bidding unit to win the bid, and should clarify or promise in writing about the vagueness in the commercial bid to avoid hidden dangers and avoid as much as possible win the bid at a low price and settle at a high price.

\subsection{Strictly monitor project changes and claims}

The project implementation stage is the most difficult and complicated stage of investment control. For a project, no change is relative and change is absolute. For the change contact list involving cost adjustment, the supervisor, the owner and the construction enterprise shall go through the review procedure of the unified engineering change, check at all levels, and make timely calculations in accordance with the contract. For unbalanced projects with large deviations, they were discovered in time during the construction process, and they were consulted with the construction unit to propose solutions to try to solve them properly during the construction process to avoid skinning after completion.

The bidding unit won the bid at a lower price in the fierce bidding competition. For the threat of losses due to changes in conditions during the construction process, it is bound to look for all possible opportunities to reduce its own risks. According to statistics, international projects can increase profits by $3 \%-5 \%$ through project management, and can increase profits by $10-20 \%$ through claims management; the average number of claims for each project is 20 , and the claim success rate about $93 \%$ [5]. This shows that the claim is a very important factor affecting the cost of the project. In order to effectively control the cost of the project, the owner must clarify responsibility for the claims, timely file counter-claims, review and amend the claims made by the contractor, carefully check the settlement of the claims, and try to recover unnecessary economic losses and better ensure the realization of engineering goals

\section{Conclusion}

The serious unbalanced quotation of the biddersr is not conducive to the perspective of owner's selection of the best contractor, which will affect the development of the fair competition mechanism in the construction market and cause the perspective of owner's investment out of control. Accordingly the perspective of owner should identify actively and guard against unbalanced quotation.

\section{References}

1. Li, M.X. Bidding \& Contract Management of Construction Projects, Xi'an, Xi 'an University of Technology Press, 2015.

2. Yang, R., Wang, Z. Engineering Bidding \& Contract Management Practice, Beijing, China Machine Press, 2015.

3. Wang, Z.W., Wang, S.H. Discussion on Unbalanced Quotation under Bill of Quantities Model, Ju Ye, 2019(10):124-125.

4. Wang, M.P. Discussion on Unbalanced Quotation of Bill of Quantities Model, Building Economy, 2019(04):79-81.

5. Liang, C. Research on Claims Management in International Engineering Projects, Master Thesis, 
University of International Business \& Economics,

Beijing, 2018. 